\title{
Bacteriological Profile and Antibiotic Susceptibility Pattern of Neonatal Septicemia in a Tertiary Hospital in Vadodara, Gujarat
}

\author{
Saurabh Chhotalal Gamit* (D), Rachana Dhirubhai Patel (D, \\ Himani Bhardwaj Pandya (D) and Sucheta Jitendra Lakhani $(\mathbb{D}$ \\ Department of Microbiology, Smt. BK Shah Medical Institute \& Research Centre, \\ Sumandeep Vidyapeeth Deemed to be University, Piparia - 391 760, Vadodara, Gujarat, India.
}

\begin{abstract}
Neonatal septicemia is a major cause of infection and mortality in neonates. Neonatal sepsis is a type of neonatal infection, particularly bacteremia, diagnosed by the presence of microorganisms in blood via microbiological culture tests during the first 4 weeks of birth. Neonatal sepsis is classified into early bacterial neonatal septicemia (less than $72 \mathrm{~h}$ ) and late bacterial neonatal septicemia (>72 h-28 d) according to age. Isolation of septicemia-causing bacteria from the blood of neonates and investigation of their antibiotic susceptibility pattern for disease management. This study was a retrospective analysis of blood cultures from neonates admitted to the NICU with symptoms of septicemia from June to December, 2019. All samples were processed according to standard microbiological procedures using the BACTEC 9050 automated culture system. Results were reported on the basis of microbial appearance on the culture media and microscopic examination using the Gram staining method, and authentication was performed using standard biochemical reactions. Of the 228 patients, $32.89 \%$ were positive for blood culture. Early bacteremia was detected in $64 \%$ of the patients, and late bacteremia was detected in $36 \%$ of the patients. The most effective drugs against the gram-positive bacteria were linezolid, vancomycin, and ciprofloxacin and against the gram-negative bacteria were tigecycline, imipenem, and amikacin. Coagulase-negative staphylococci and gram-negative organisms such as Klebsiella, Acinetobacter, and Staphylococcus aureus were the major cause of neonatal septicemia in this study, and almost all the isolates were resistant to different antibiotics. Overall, antimicrobial drug resistance was observed in all the positive blood culture samples.
\end{abstract}

Keywords: Neonatal septicemia, blood culture, antibiotics, antibiotic susceptibility

*Correspondence: saurabhgamit@gmail.com; +91 9106276223

(Received: March 11, 2021; accepted: January 31, 2022)

Citation: Gamit SC, Patel RD, Pandya HB, Lakhani SJ. Bacteriological Profile and Antibiotic Susceptibility Pattern of Neonatal Septicemia in a Tertiary Hospital in Vadodara, Gujarat. J Pure Appl Microbiol. 2022;16(1):638-642. doi: 10.22207/JPAM.16.1.65

(C) The Author(s) 2022. Open Access. This article is distributed under the terms of the Creative Commons Attribution 4.0 International License which permits unrestricted use, sharing, distribution, and reproduction in any medium, provided you give appropriate credit to the original author(s) and the source, provide a link to the Creative Commons license, and indicate if changes were made. 


\section{INTRODUCTION}

Neonatal septicemia is one of the most common causes of infection and mortality in neonates, due to which $30-50 \%$ of neonates die each year in developing nations. Various studies have suggested that bacteremia occurs in $20 \%$ of neonates, and approximately $1 \%$ die due to neonatal sepsis. ${ }^{1}$ According to the National Perinatal Database (NNPD) study, neonatal septicemia occurred in 30 live births out of 1000 in India during 2002-2003. ${ }^{2}$ The classification of neonatal sepsis is based on the age at infection initiation; according to this classification, it is categorized into early bacterial neonatal sepsis (less than $72 \mathrm{~h}$ ) and late bacterial neonatal sepsis (>72 h-28 d). Early bacterial neonatal septicemia is diagnosed mostly at the time of fetal delivery and during the nursery period. ${ }^{4}$ There are various gram-positive and gram-negative bacteria that cause bacterial neonatal septicemia. ${ }^{5}$

Currently, the appearance of multiple antibiotic-resistant microorganisms poses challenges in the management of neonatal sepsis. ${ }^{6,7}$ In order to utilize the antimicrobial therapy effectively in septicemia patients to detect the prevalence of bacteria and the related antibiotic drugs, it is important to identify their sensitivity patterns. Early detection and antimicrobial treatment in sepsis are useful for reducing morbidity and mortality. ${ }^{8}$ This study was performed in an institute to determine the incidence rate and microbiological profile of neonatal sepsis along with the antibiotic susceptibility testing (AST) pattern of the isolates from neonates who were admitted to the NICU of Dhiraj Hospital, Pipariya, Vadodara.

\section{MATERIALS AND METHODS}

This study was conducted in the central laboratory of the Department of Microbiology, Dhiraj Hospital, Vadodara (Gujarat) from June to December, 2019. The study evaluated the bacteriological profile and antibiotic susceptibility patterns of 228 neonates clinically suspected of septicemia, admitted to the NICU of Dhiraj Hospital, Piparia, Vadodara (Gujarat) from June to December, 2019.

Blood samples were collected from suspected neonates with septicemia under aseptic conditions after obtaining consent from their relatives. Then, $1-2 \mathrm{ml}$ of the collected venous blood was inoculated in a blood culture bottle containing $40 \mathrm{ml}$ sterile BD BACTEC ${ }^{\mathrm{TM}}$ Peds $\mathrm{Plus}^{\mathrm{TM}} / \mathrm{F}$ culture vials. All samples were processed according to standard microbiological procedures using the BACTEC 9050 automated culture system. If microbes are present in the collected blood specimen injected into the sterile bd bactec peds plus/ $f$ culture vials, $\mathrm{CO}_{2}$ is generated when the microbes break down the substance present in the vial. The rise in the fluorescence of the vial due to the higher amount of $\mathrm{CO}_{2}$ released by microbes was monitored using the BD BACTEC 9050 instrument. The positive blood cultures were subcultured on sheep blood agar and MacConkey agar and incubated at $37^{\circ} \mathrm{C}$ for $24 \mathrm{~h}$.

\section{Statistical analysis}

Results were reported on the basis of the appearance of microbial growth on culture media and microscopic examination using the Gram staining method, and interpretation was performed using standard biochemical reaction tests. Several bacteria from the Enterobacteriaceae family have been identified using various biochemical reactions such as indole test, $\mathrm{H}_{2} \mathrm{~S}$ production-based catalase test, citrate utilization test, hanging drop test, urease test, oxidase test, sugar fermentation test, and other tests. For gram-positive bacteria, coagulase, catalase, bacitracin, and optochin disk tests and other tests were performed. The correlation of the results was also performed using BioMerieux's VITEK ${ }^{\circledast} 2$ COMPACT (automated microbial identification system).

The antimicrobial susceptibility test was performed on Muller Hilton agar (MHA) using the Kirby-Bauer disc-diffusion antibiotic sensitivity test method in accordance with the Clinical Laboratory Standards Institutes (CLSI) guidelines. ${ }^{9}$ Following drugs were used for the disc-diffusion antibiotic sensitivity test: For gram-positive bacteria: penicillin (10 units), levofloxacin $(5 \mu \mathrm{g})$, ciprofloxacin $(5 \mu \mathrm{g})$, gentamicin $(10 \mu \mathrm{g})$, vancomycin $(5 \mu \mathrm{g})$, and linezolid $(30 \mu \mathrm{g})$. For gram-negative organisms, ampicillin $(10 \mu \mathrm{g})$, ciprofloxacin $(5 \mu \mathrm{g})$, gentamicin (10 and $30 \mu \mathrm{g}$ ), co-trimoxazole (1.25 $\mu \mathrm{g}$ trimethoprim/23.75 $\mu \mathrm{g}$ sulfamethoxazole), amikacin $(30 \mu \mathrm{g})$, cefepime $(5 \mu \mathrm{g})$, ceftriaxone (30 $\mu \mathrm{g})$, imipenem $(10 \mu \mathrm{g})$, piperacillin/tazobactam $(100 / 10 \mu \mathrm{g})$, and tigecycline $(15 \mu \mathrm{g})$. The discs were obtained from HiMedia Laboratories (India). ${ }^{9}$ 
Table 1. Main Causal bacteria for Neonatal septicemia

\begin{tabular}{lccc}
\hline Isolated bacteria & $\begin{array}{c}\text { Total } \\
(\mathrm{n}=75)\end{array}$ & $\begin{array}{c}\text { EOS } \\
(\mathrm{n}=48)\end{array}$ & $\begin{array}{c}\text { LOS } \\
(\mathrm{n}=27)\end{array}$ \\
\hline \multicolumn{4}{c}{ Gram-positive bacteria $(\mathrm{n}=46)$} \\
\hline 1. CONS & $35(46.67 \%)$ & 20 & 15 \\
2. Staphylococcus & $11(14.67 \%)$ & 09 & 02 \\
& aureus & & \\
\hline \multicolumn{4}{l}{ Gram-negative bacteria $(\mathrm{n}=29)$} \\
1. Klebsiella spp. & $13(17.33 \%)$ & 10 & 03 \\
2. Acinetobacter spp. & $12(16 \%)$ & 07 & 05 \\
3. E. coli & $03(4 \%)$ & 01 & 02 \\
4. Pesudomonas & $01(1.33 \%)$ & 01 & -
\end{tabular}

\section{RESULTS}

A total of 228 suspected neonatal blood samples were collected for blood culture during the study; among these, bacterial sepsis was confirmed in $32.89 \%$ ( 75 out of 228 ) patients. Of the 75 patients, 48 (64\%) had early septicemia (EOS; $<72 \mathrm{~h}$ of age) and 27 (36\%) had late septicemia (LOS; $>72$ h of age).

In this study, 46 gram-positive and 29 gram-negative bacteria were isolated. Among these, coagulase-negative staphylococci (CONS) were detected in $46.67 \%$ (35 out of 75 ), gramnegative Klebsiella spp. in $17.33 \%$ (13 out of 75 ), Acinetobacter in $16 \%$ (12 out of 75), and Staphylococcus aureus in $14.67 \%$ of the patients (11 out of 75). The main causal bacteria for septicemia are listed in Table 1.

Table 2 suggests that the most sensitive antibiotics to gram-positive bacteria were vancomycin and linezolid, followed by ciprofloxacin and gentamicin. Almost all the gram-positive bacteria were resistant to penicillin.

Table 3 suggests that the most sensitive antibiotics to gram-negative bacteria were tigecycline, imipenem, and piperacillin/ tazobactam, followed by ciprofloxacin and amikacin. Almost all the gram-negative bacteria were resistant to ampicillin and co-trimoxazole.

\section{DISCUSSION}

This study shows that gram-positive bacteria such as Klebsiella, Acinetobacter, CONS, and $S$. aureus are the major cause of neonatal septicemia, and most of them are resistant to multiple antibiotics that are routinely used.
Table 2. Antibiotic susceptibility of gram-positive bacteria $(n=46)$

\begin{tabular}{lcc}
\hline Antibiotic & Resistant (\%) & Sensitive (\%) \\
\hline Penicillin (P) & $40(87)$ & $06(13)$ \\
Levofloxacin (LE) & $31(67)$ & $15(33)$ \\
Gentamicin (GEN) & $23(50)$ & $23(50)$ \\
Ciprofloxacin (CIP) & $22(47)$ & $24(52.1)$ \\
Vancomycin (VA) & - & $46(100)$ \\
Linezolid (LZ) & - & $46(100)$ \\
\hline
\end{tabular}

Table 3. Antibiotic susceptibility of gram-negative bacteria $(n=29)$

\begin{tabular}{lcc}
\hline Antibiotics & Resistant (\%) & Sensitive (\%) \\
\hline Ampicillin (AMP) & $28(97)$ & $01(03)$ \\
Co-trimoxazole (COT) & $20(69)$ & $09(31)$ \\
Cefepime (CPM) & $19(65)$ & $10(35)$ \\
Ceftriaxone (CTR) & $18(62)$ & $11(38)$ \\
Gentamicin (GEN) & $16(55)$ & $13(45)$ \\
Amikacin (AK) & $13(45)$ & $16(55)$ \\
Ciprofloxacin (CIP) & $07(24)$ & $22(76)$ \\
Piperacillin/ & $06(21)$ & $23(79)$ \\
tazobactam (PT) & & \\
Imipenem (IPM) & $04(14)$ & $25(86)$ \\
Tigecycline (TGC) & $01(03)$ & $28(97)$ \\
\hline
\end{tabular}

Table 4 shows that in the four studies, the prevalence of neonatal septicemia was did not differ considerably, which indicates that the prevalence of neonatal septicemia is high in developing countries such as India.

Table 5 shows that in most of the studies compared, neonatal septicemia was caused by Klebsiella, Acinetobacter, Coagulase-negative Staphylococcus (CONS), and Staphylococcus aureus. The most typical organism was Klebsiella. 
Table 4. Comparison of the prevalence of neonatal septicemia reported in different studies

\begin{tabular}{lcccc}
\hline Parameter & This study & Muley et al. ${ }^{10}$ & Kumar et al. ${ }^{11}$ & Thakur et al. ${ }^{12}$ \\
\hline Prevalence & $32.89 \%$ & $26.6 \%$ & $26.2 \%$ & $42 \%$ \\
\hline
\end{tabular}

Table 5. Comparison of the organisms isolated from blood culture of neonatal septicemia samples

\begin{tabular}{lcccc}
\hline Organism & This study & Jyothi et al. $^{13}$ & Yadav et al. ${ }^{14}$ & Roy et al. ${ }^{15}$ \\
\hline CONS & $46.67 \%$ & $27.5 \%$ & $10.2 \%$ & $16.6 \%$ \\
Klebsiella & $17.33 \%$ & $30.5 \%$ & $15.3 \%$ & $24.6 \%$ \\
Acinetobacter & $16 \%$ & $12.2 \%$ & $11.9 \%$ & - \\
Staphylococcus & $11 \%$ & $10.6 \%$ & $35.6 \%$ & $14 \%$ \\
\hline
\end{tabular}

Table 6. Comparison of the antibiotic susceptibility pattern of blood culture isolates from neonatal septicemia samples

\begin{tabular}{lcccccc}
\hline Antibiotics & \multicolumn{2}{c}{ This study } & \multicolumn{2}{c}{ Jyothi et al. ${ }^{13}$} & \multicolumn{2}{c}{ Muley et al. ${ }^{10}$} \\
\hline Gram-negative bacteria & $\begin{array}{c}\text { Resistant } \\
(\%)\end{array}$ & $\begin{array}{c}\text { Sensitive } \\
(\%)\end{array}$ & $\begin{array}{c}\text { Resistant } \\
(\%)\end{array}$ & $\begin{array}{c}\text { Sensitive } \\
(\%)\end{array}$ & $\begin{array}{c}\text { Resistant } \\
(\%)\end{array}$ & $\begin{array}{c}\text { Sensitive } \\
(\%)\end{array}$ \\
\hline Imipenem & 03 & 97 & 07 & 93 & 00 & 100 \\
Amikacin & 45 & 55 & 48 & 52 & 35.3 & 64.7 \\
Gentamicin & 55 & 45 & 49 & 51 & 41.2 & 58.8 \\
Ampicillin & 97 & 03 & 97 & 03 & 70.5 & 29.5 \\
\hline Gram-positive bacteria & Resistant & Sensitive & Resistant & Sensitive & Resistant & Sensitive \\
& $(\%)$ & $(\%)$ & $(\%)$ & $(\%)$ & $(\%)$ & $(\%)$ \\
\hline Linezolid/Vancomycin & 00 & 100 & 09 & 91 & 0 & 100 \\
Ciprofloxacin & 47 & 53 & 48 & 52 & 27.3 & 72.7 \\
Gentamicin & 55 & 45 & 60 & 40 & 44.5 & 55.5 \\
Penicillin & 87 & 13 & 90 & 10 & 72.7 & 27.3 \\
\hline
\end{tabular}

\section{Limitation}

Although we aimed to include all patients during the indicated period, data were limited due to the prevalence of this disease. Furthermore, we found that the automated instruments failed to isolate a few organisms. In such patients, confirmation and identification via traditional methods are useful; however, we used only preliminary tests for such patients. More sensitive automation may be required in such patients.

\section{CONCLUSION}

Neonatal mortality and morbidity associated with bacterial neonatal septicemia can be attributed to a variety of gram-positive and gram-negative bacteria with different sensitivity patterns in different geographic areas and populations. We suggest that any suspected case of bacterial septicemia, particularly in NICU settings, should undergo bacterial culture and sensitivity profiling, and disease management should be performed according to the isolated and detected organism and its sensitivity to antibiotics.

\section{ACKNOWLEDGMENTS}

The authors are thankful to the institution for granting permission to carry out the study and to the teaching staff of the Microbiology Department of SBKS MI \& RC and Central Laboratory Dhiraj Hospital, Vadodara, India for 
their advice and support. They are grateful for the cooperation of the patients who participated in this study.

\section{CONFLICT OF INTEREST}

The authors declare that there is no conflict of interest.

\section{AUTHORS' CONTRIBUTION}

All authors listed have made a substantial, direct and intellectual contribution to the work, and approved it for publication.

\section{FUNDING}

None.

\section{DATA AVAILABILITY}

All datasets generated or analyzed during this study are included in the manuscript.

\section{ETHICS STATEMENT}

This study was approved by the Institute Ethics Committee, Sumandeep Vidhyapeeth University, Vadodara, India.

\section{REFERENCES}

1. Tripathi S, Malik GK. Neonatal sepsis: Past, present and future; a review article. Internet J Med Update. 2010;5(2):45-54. doi: 10.4314/ijmu.v5i2.56163

2. Report of the National Neonatal Perinatal Database. Report 2002-2003. NNPD Network. http://www. newbornwhocc.org/pdf/nnpd_report_2002-03.PDF. Accessed on 2010 July 17.

3. Puopolo KM. Bacterial and fungal infection. In: Cloherty JP, Eichenwald EC, Stark AR,editors. Manual of Neonatal care, 6th ed. Philadelphia: Lippinco William and Wilkins; 2008:274-300.

4. Gomaa HHA, Udo EE, Rajaram U. Neonatal septicemia in Al Jahra hospital, Kuwait: Etiologic agents and antibiotic sensitivity patterns. Med Princ Pract 2001;10:145-155. doi: 10.1159/000050359
5. Shrestha RK, Rai SK, Khanal LK, Mandal PK. Bacteriological study of Neonatal sepsis and antibiotic susceptibility pattern in Kathmandu, Nepal. Nepal Med Coll J. 2013;15:71-73.

6. Shrestha NJ, Subedi KU, Rai GK. Bacteriological profile of Neonatal sepsis: a hospital based study. J Nep Paedtr Soc. 2011;31(1):1-5. doi: 10.3126/jnps.v31i1.4158

7. Levy I, Leibovici L, Ducker M, Samra Z, Konisberger $\mathrm{H}$, Ashkenazi S. A prospective study of Gramnegative bacteraemia in children. Pediatr Infect Dis J. 1996;15(2):117-122. doi: 10.1097/00006454199602000-00006

8. Collee JG, Marr W. Culture of Bacteria. In: Collee JG, Fraser AG, Marmion BP, Simmons A, editors. Mackie and McCartney Practical Medical Microbiology. 14 ${ }^{\text {th }}$ ed. New York: Churchill Livingstone; 1996:113-129.

9. CLSI. Performance Standards for Antimicrobial Susceptibility Testing. $28^{\text {th }}$ ed. CLSI supplement M100. Wayne, PA: Clinical and Laboratory Standards Institute; 2018.

10. Muley VA, Ghadage DP, Bhore AV. Bacteriological Profile of Neonatal Septicemia in a Tertiary Care Hospital from Western India. J Glob Infect Dis. 2015;7(2):75-77. doi: 10.4103/0974-777X.154444

11. Pavan Kumar DV, Mohan J, Rakesh P S, Prasad J, Joseph L. Bacteriological profile of Neonatal sepsis in a secondary care hospital in rural Tamil Nadu, Southern India. J Family Med Prim Care. 2017;6(4):735-738. doi: 10.4103/jfmpc.jfmpc_66_17

12. Thakur S, Thakur K, Sood A, Chaudhary S. Bacteriological profile and antibiotic sensitivity in rural tertiary care hospital in north india. Indian J Med Microbiol. 2016;34(1):67-71. doi: 10.4103/0255-0857.174108

13. Jyothi P, Basavaraj MC, Basavaraj PV. Bacteriological profile of Neonatal septicemia and antibiotic susceptibility pattern of the isolates. J Nat Sci Biol Med. 2013;4(2):306-309. doi: 10.4103/0976-9668.116981

14. Yadav NS, Sharma S, Chaudhary DK, et al. Bacteriological profile of Neonatal sepsis and antibiotics susceptibility pattern of isolates admitted at Kanti Children's Hospital, Kathmandu, Nepal. BMC Res Notes. 2018;11(1):301. doi: 10.1186/s13104-018-3394-6

15. Roy I, Jain A, Kumar M, Agarwal SK. Bacteriology of Neonatal septicemia in a tertiary care hospital of northern India. Indian J Med Microbiol. 2002;20(3):156159. doi: $10.1016 / \mathrm{S} 0255-0857(21) 03250-3$ 